\title{
Development of a Mobile-Based Hypertension Risk Monitoring System
}

\author{
Ngozi C. Egejuru \\ Hallmark University, Department of Computer Science, Ijebu Itele, Ogun State, Nigeria \\ Email: ngoegejuru@yahoo.com \\ Oluwadare Ogunlade \\ Obafemi Awolowo University, Department of Physiological Sciences, Ile-Ife, Osun State, Nigeria \\ Email: oogunlade@oau.edu.ng

\begin{abstract}
Peter A. Idowu
Obafemi Awolowo University, Department of Computer Science \& Engineering, Ile-Ife, Osun State, Nigeria Email: paidowu1@yahoo.com, paidowu@ oauife.edu.ng
\end{abstract}

Received: 27 February 2019; Accepted: 22 April 2019; Published: 08 July 2019

\begin{abstract}
Hypertension is a silent killer, which gives no warning signs to alert a patient and can only be detected through regular blood pressure checkups. Uncontrolled and unmonitored hypertension contributed to stroke, chronic kidney disease, eye problem, and heart failure. It is an ongoing challenge to health care systems worldwide. Early detection of hypertension and creating awareness will greatly reduce the effect of hypertension and its related diseases. Also, having a mobile-based system will help patients to know their status, relate with Doctor and enjoy the quick response from the Doctor on hypertension diagnostic effect on their health. The mobile application will help in monitoring patients anytime, anywhere and provide services for each patient based on their personal health condition. The mobile application was designed using unified modeling language and implemented using the Extensible Mark-Up Language and Java programming language for the mobile layout and content, while JavaScript Object Notation was used to implement the data storage and retrieval mechanism of the system. The system was tested using data collected from hospital, which yielded an accuracy of $100 \%$. In conclusion, the system will assist in providing timely, efficient, accurate and comprehensive information about hypertension, which is useful for Doctors and patients in detecting, diagnosing, classifying and managing hypertension and its risk.
\end{abstract}

Index Terms-Classification, Diagnosis, Hypertension, Mobile-based, Monitoring, Risk

\section{INTRODUCTION}

Uncontrolled hypertension is an ongoing challenge to health care systems worldwide [1]. When hypertension is poorly controlled, it increases mortality, morbidity, and economic burden especially among older adults, and it is a major public health concern all over the world, [2].

Hypertension or high blood pressure (HBP) is a cardiac chronic medical condition in which the systemic arterial blood pressure is elevated [3]. Hypertension condition is categorized as either primary (essential) or secondary hypertension. Primary hypertension does not have a clear ${ }^{1}$ medical cause, while secondary hypertension is linked to identifiable causes such as vascular disorder, kidney diseases or endocrine [4,5].

Hypertension is diagnosed with persistent elevation of the systolic blood pressure $(\mathrm{SBP}) \geq 140 \mathrm{mmHg}$ and diastolic blood pressure (DBP) $\geq 90 \mathrm{mmHg}$ based on the average of two or more correct blood pressure measurement taken two or more contact with healthcare providers [6]. Globally, the overall prevalence of hypertension in adults from age 25 and over, was around $40 \%$ in 2008 [7].

It is vital to control illness, which involves carrying out necessary investigations, essential enquiries into the patient history and the administration of therapy by the Doctor (medical practitioner). The essence of this, is to ensure that the patients BP remain within the normal range [8]. Hypertension is the leading and most essential modifiable risk factor for heart diseases, renal diseases, stroke, and retinopathy [9].

In Sub-Saharan Africa, studies have shown that uncontrolled hypertension contributed to stroke, chronic kidney disease, retina (sight) problem, aortic dissection and heart failure [4]. Surveys in some countries on blood pressure (BP) showed that less than $25 \%$ of patients with hypertension are under good BP control [1].

According to Logan et al. [10], concern over the rise in a poor level of blood pressure (BP) control among patients with hypertensive, has led to serious early search

\footnotetext{
${ }^{1}$ 2019-03-12 10:09:31 manuscript submission

2019-04-23 18:40:51 submitted copyright agreement
} 
for new ways of managing hypertension. Also, patients are willing to become more actively involved in managing their own healthcare [11]. Introduction of selfmonitoring whether at home or office, in short, any location becomes a way of increasing patient's involvement in managing hypertension.

A disease risk monitoring includes the automation of the risk assessment of diseases, which provides cost savings for the patients/hospitals management, and increases the efficiency of the specialists [12,13,14]. Using information and communication technology (ICT), which involves mobile computing, distributed computing, and the internet, can provide healthcare service to monitor hypertension and its risk anytime, and anywhere.

Mobile technology is an ubiquitous tool in managing everyday life over a variety of applications. It can be used by an intending user to provide quality healthcare service from any remote location and is very portable thereby making services easily accessible and available. Mobile technology can assist in developing a system that has a communication platform for patients and doctors. With the use of mobile technologies, hypertension risk can be easily identified and managed by doctors and patients. Patients will be directed to conduct necessary investigations to know their health status.

The need to develop and organize new ways of providing effective and efficient healthcare service has increased with the use of Information Technology $[15,16]$. The use of IT in healthcare service (e-Health), involves using communication technologies, such as the internet, computer systems, portable, wireless and other devices in support of healthcare delivery and education $[17,18]$. eHealth entails a fundamental redesign of healthcare processes based on the use and integration of electronic communications in all levels. The medical information of a patient can be stored electronically, and be used in decision making concerning the patient's treatment and health. It will help in providing reliable, flexible, timely and secure healthcare delivery to patients by the medical practitioners.

The integration of clinical decision support system might decrease medical errors, enhance the patient result, decrease unwelcome practice disparity, and improve patient's protection [19]. The integration of computing platforms and wireless communication technologies in healthcare systems has enhanced the quality of health service for millions of people all over the world [20]. The use of ICT has brought revolution to healthcare services and using mobile technology will provide the ability to instantly update patient's records, which will help the medical practitioners to make the more accurate decision and enhance quality care for patients, which will also help in early detection, diagnosis, and management of patient's health.

There is a need to design the processes that are centred on the need of patients [21] and elicit knowledge from the experts on the processes involved. This will enable patients to easily access the required information needed in taking care of their own health. Medical decision support systems are becoming more and more essential in assisting the doctors to take correct decisions [22]. There is a need for the development of a mobile-based system for the classification of the risk of hypertension. This will enhance early detection of the disease for providing clinical decision support and improving the living standard of the patients.

The aim of this study is to build a mobile-based classification system called BP_HRMSystem that can identify or diagnose individuals suffering from hypertension, classify and manage the hypertension risk, which will greatly help in creating awareness.

This system has a communication platform that can allow the doctor and patient to communicate with each other through the administrator. The patient can leave messages for the doctor and get related advice from the doctor. Then, medical practitioners can check the messages and give related answers or replies. Moreover, the medical practitioner can give some advice when they view the current condition of the patient. This will help the patient to take the right steps or treatment required.

The system has a knowledgeable database that can be used to guide patients and medical practitioners. The system keeps track of the patient's medical history and is able to plot a graph on the blood pressure of the patient. The patient and the medical practitioner can see the way the blood pressure is fluctuating, evaluate the patient and make decisions. The system keeps track of the body mass index (BMI) of the patient, which can be seen at a glance.

\section{RELATED WORKS}

Reference [10] worked on Mobile Phone-Based Remote Patient Monitoring System for Management of Hypertension in Diabetic Patients. The study developed and pilot-tested a home BP tele-management system that actively engages patients in the process of care. The system, developed using commodity hardware, comprised a Bluetooth-enabled home BP monitor, a mobile phone to receive and transmit data, a central server for data processing, a fax-back system to send physicians' reports, and a BP alerting system. In the pilot study, 24-h ambulatory BP fell by $11 / 5( \pm 13 / 7 \mathrm{SD}) \mathrm{mm}$ $\mathrm{Hg}$ (both $P<.001$ ), and BP control improved significantly. The results of the study showed that the system improved BP control and used only the BP readings. The system did not handle $\mathrm{BP}$ classification and its risk. The variables used were not enough in taking decisions on hypertension risk, according to WHO/ISH guidelines [23].

Reference [24] proposed a health monitoring system for hypertensive patients in rural Nigeria. A simulation of a real-time mobile health monitoring system was proposed using GPRS-enabled technology. UML design was used to design the data model for the monitoring system, while the system was implemented using JAVA. The result of the study showed that medical data could be routed from mobile sensor implants using GPRS to patients' records, which can be interpreted by the specialists. The system was limited only to the storage 
and retrieval of information, and cannot classify hypertension risk.

Reference [5] proposed a framework for intelligent remote monitoring and control of blood pressure in developing nations. The study involved the application of wireless communication and remote sensing technologies to monitor the vital signs of individuals with high blood pressure. The result of the study was limited to the monitoring of high blood pressure with no adherence to the effect of high blood pressure on the individuals monitored, for example, hypertension risk assessment. There are other important vital signs in the human body that requires monitoring alongside the blood pressure, which was not considered.

Reference. [25] developed a real-time blood pressure, temperature measurement and reporting system for inpatients. The function of this system is to constantly measure the blood pressure and temperature of a patient and send the measured values to the medical doctor or other relevant caregivers through a wireless link. The system is built around the STM32F103C8 Microcontroller programmed in $\mathrm{C}$ language which performs the overall control action and interfaces with other peripherals like MPX5050GP and the DS18B20 which acts as primary sensors for blood pressure and temperature respectively. The health monitoring system was designed, constructed and tested. The results of blood pressure and body temperature measurements were compared with those of an OMRON blood pressure monitor and a clinical thermometer respectively. The variables used were not enough in taking decisions on hypertension risk according to WHO/ISH guidelines.

Reference [26] developed a web-based cardiovascular disease monitoring system for heart failure cases in western Nigeria which can be accessed by authorized healthcare providers and public health officers alike. The system was designed using unified modeling language (UML) tools and implemented using Web 2.0 technologies. The implemented web-based cardiovascular disease monitoring system was hosted locally using the Web-Apache-MySQL-PHP (WAMP) server. The implemented system was tested for functionality and usability based on the information provided and retrieved by the users and healthcare providers respectively. It actually developed for heart disease specifically with different variables.

Considering the foregoing reviews in the area of hypertension and its risk, there is no existing validated system for hypertension risk that meets or near the WHO/ISH guidelines available for use. Globally, hypertension is a major chronic disease and it is considered by the World Health Organization (WHO) to be a leading cause of death and disability in economically developing countries [27]. Untreated, uncontrolled and unmonitored hypertension increases the risk of damage to the arteries, heart attack, stroke, and it is responsible for other conditions such as pre-eclampsia and other cardiac illnesses. The use of mobile phones, laptops, desktops and other devices with the Internet, which is gradually becoming cost efficient, can, therefore, be leveraged to help manage the risk of hypertension.

Hypertension which causes sudden death and heart attack, is a silent killer that does not give any warning sign to alert the patient, and it can only be detected through regular health checkup. According to Ordinioha [28], hypertension and other non-communicable diseases (NCD) are currently responsible for at least $20 \%$ of all deaths in Nigeria, and form up to $60 \%$ of the patients that are admitted into the medical wards of most tertiary hospitals in Nigeria. Globally, lack of appropriate systems for monitoring hypertension has contributed to global cases of cardiovascular related diseases and deaths. Although there are some existing models or systems which consider a few clinical variables for determining hypertension risk, however, wrong diagnosis and classification persist. There are no existing monitoring systems for hypertension risk class that have considered all possible risk factors as stated by 1999 WHO/ISH guidelines. In order to handle the menace of hypertension, patients need to have adequate knowledge of their blood pressure level and hypertension risk status. It is very important to create awareness of hypertension as a disease and empower people with the knowledge and tools to prevent or manage hypertension.

This necessitated the need for a computer-based system that will help both the patient and the medical practitioners in creating awareness, control, and monitoring patients with hypertension, thereby reducing overall morbidity and mortality relating to hypertension. There is need to develop a mobile-based system that will be suitable for hypertension risk classification, which will enable accurate diagnosis and management of hypertension that will help medical practitioners to diagnose, classify and manage patients with hypertension and also allow easy access to medical practitioners by patients from any remote location real-time.

This study describes the development of a mobilebased hypertension monitoring system to assist hypertensive patients to monitor their blood pressure, identify people that are hypertensive, and have effective blood pressure control from a specialist.

\section{METHODS}

In order to classify hypertension risk, which is in line with 1999 WHO/ISH hypertension classification standard, thirty-three variables were identified as shown in Table 1, Table 2 and Table 3 . These variables were classified into 6 groups namely, systolic blood pressure (SBP), diastolic blood pressure (DBP), diabetes mellitus, other risk factors, target organ damage (TOD) and associated clinical conditions (ACC). The SBP and DBP of patients were classified further into hypertension levels of: normal; grade I; grade II and grade III (Table 4), based on three consecutive readings of the SBP and DBP. 
Table 1. Identified Variables (factors) for Hypertension Risk Monitoring System

\begin{tabular}{|l|l|}
\hline $\begin{array}{l}\text { Number of } \\
\text { Variables }\end{array}$ & Names of Variables \\
\hline 1 & Level of Systolic Blood Pressure \\
\hline 2 & Level of Diastolic Blood Pressure \\
\hline 3 & Diabetes \\
\hline 4 & Gender \\
\hline 5 & Age - Men $>=55$ years and Women $>=65$ years \\
\hline 6 & Smoking \\
\hline 7 & Alcohol \\
\hline 8 & Exercise \\
\hline 9 & Total cholesterol $>6.5$ mmo/l $(250 \mathrm{mg} / \mathrm{dl})$ \\
\hline 10 & Family History of hypertension \\
\hline 11 & Family History of heart disease \\
\hline 12 & Stress at workplace \\
\hline 13 & Salt intake \\
\hline 14 & Marital/Domestic issue \\
\hline 15 & Sedentary lifestyle \\
\hline 16 & Body Mass Index (BMI) (Weight and Height) \\
\hline
\end{tabular}

Table 2. Target Organ Damage Variables

\begin{tabular}{|l|l|l|}
\hline S/N & TOD Variable & Investigation \\
\hline 17 & $\begin{array}{l}\text { Left Ventricular Hypertrophy } \\
(\mathrm{LVH})\end{array}$ & $\begin{array}{l}\text { Detected using an } \\
\text { Electrocardiogram } \\
\text { (ECG) }\end{array}$ \\
\hline 18 & Presence of protein & $\begin{array}{l}\text { Detected in urine during } \\
\text { Urinalysis. }\end{array}$ \\
\hline 19 & Presence of Plaque & $\begin{array}{l}\text { Detected using } \\
\text { Ultrasound scan. }\end{array}$ \\
\hline 20 & $\begin{array}{l}\text { Presence of hypertensive } \\
\text { retinopathy }\end{array}$ & $\begin{array}{l}\text { Detected } \\
\text { Fundoscopy. }\end{array}$ \\
\hline
\end{tabular}

Table 3. Associated Clinical Conditions

\begin{tabular}{|l|l|ll|}
\hline S/N & ACC Variable & \multicolumn{2}{|c|}{ Investigation } \\
\hline 21 & Cerebrovascular & $\bullet$ & Ischemic stroke \\
22 & disease & $\bullet$ & Cerebral haemorrhage \\
23 & & $\bullet$ & Transient Ischaemic attack \\
\hline 24 & Heart diseases & $\bullet$ & Myocardial infarction \\
25 & & $\bullet$ & Angina \\
26 & & $\bullet$ & Coronary revascularization \\
27 & & $\bullet$ & Congestive heart failure \\
\hline 28 & Renal Diseases & $\bullet$ & Diabetic nephropathy \\
29 & & $\bullet$ & Renal failure (plasma \\
& & & creatinine concentration $>$ \\
& & & 2.0 mg/dl) \\
\hline 30 & Vascular & $\bullet$ & Dissecting aneurysm \\
31 & Disease & $\bullet$ & Symptomatic arterial disease \\
\hline 32 & Advanced & $\bullet$ & Haemorrhages or exudates \\
33 & hypertensive & $\bullet$ & Papilloedema \\
& retinopathy & & \\
\hline
\end{tabular}

The system checks the risk factors and other clinical information and uses the values provided to classify the hypertension risk of a patient as either, low risk, medium risk, high risk or very high risk (Table 4). Any patient, whose SBP is less than $140 \mathrm{mmHg}$ and DBP is less than $90 \mathrm{mmHg}$, was classified as no risk or normal (SBP < $140 \mathrm{mmHg}$ and DBP $<90 \mathrm{mmHg}$ ). The moment individual's blood pressure is normal, there is no risk of hypertension for the individual, the patient's hypertension risk becomes Normal.
Table 4.Stratification of Risk of Hypertension according to WHO/ISH

\begin{tabular}{|c|c|c|c|}
\hline \multirow[t]{2}{*}{$\begin{array}{lr}\text { Other Risk } \\
\text { Factors and } \\
\text { Disease History }\end{array}$} & \multicolumn{3}{|c|}{ BLOOD PRESSURE (mmHg) } \\
\hline & $\begin{array}{l}\frac{\text { Grade } 1}{\text { (Mild }} \\
\text { Hypertension } \\
\text { ) } \\
\text { SBP: } 140- \\
159 \\
\text { DBP: } 90 \text { - } 99\end{array}$ & $\begin{array}{l}\text { Grade 2 } \\
\text { (Moderate } \\
\text { Hypertension } \\
\text { ) } \\
\text { SBP: } 160 \quad- \\
179 \\
\begin{array}{lll}\text { DBP: } 100 & - \\
109 & \end{array}\end{array}$ & $\begin{array}{l}\text { Grade } 3 \\
\text { (Severe } \\
\text { Hypertension } \\
\text { ) } \\
\text { SBP: } \geq 180 \\
\text { DBP: } \geq 110\end{array}$ \\
\hline No risk factor & LOW & MEDIUM & HIGH \\
\hline $1-2$ risk factor & MEDIUM & MEDIUM & VERY HIGH \\
\hline $\begin{array}{l}3 \text { or more risk } \\
\text { factor or TOD } \\
\text { or diabetes }\end{array}$ & HIGH & HIGH & VERY HIGH \\
\hline ACC & VERY HIGH & VERY HIGH & VERY HIGH \\
\hline
\end{tabular}

Based on the variables and 1999 WHO/ISH stratification for hypertension risk classification, an ANFIS model was formulated.

\section{A. Adaptive Neuro-Fuzzy Inference System (ANFIS) for Hypertension Risk}

Following the identification of the variables required for the risk of hypertension in patients, the classification model needed for the determination of the risk of hypertension was formulated using the ANFIS model. As a result of the fuzzy nature exhibited in the blood pressure levels and the number of risk factors collected, the fuzzy-based model was required for the formulation of the classification model. The ANFIS model is a fuzzy-based model which had an advantage over existing fuzzy logic models due to its adaptive nature, which is as a result of the ability to train the model from a historical dataset. The ANFIS model was used due to its ability to combine the functionality of the Takagi-Sugeno fuzzy model and the neural network architecture.

The Takagi-Sugeno and neuro-fuzzy systems made use of the back-propagation algorithm to learn the membership functions and least mean square estimation to determine the coefficients of the linear combinations of the inference rule's conclusions from the training data collected for this study. Fig.1. shows the structure of the ANFIS model for hypertension risk classification.

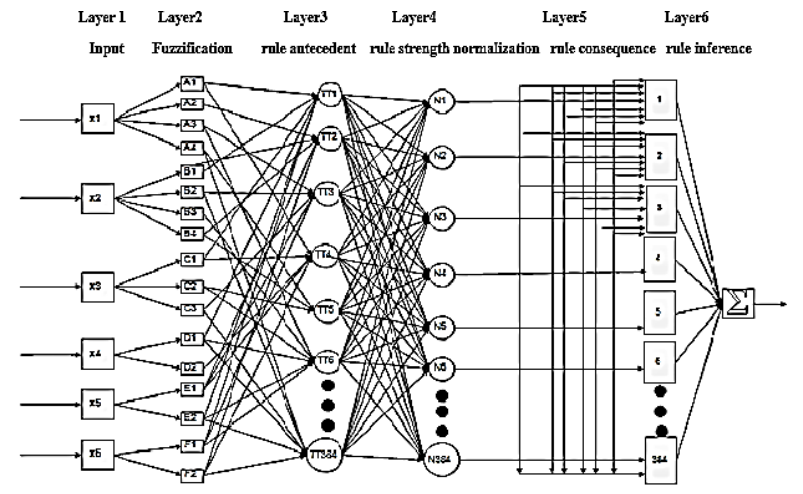

Fig.1. The Structure of ANFIS Model for Hypertension Risk 
The different composite layers of the ANFIS model are:

i. Layer-1 (input layer): No computation was performed at this layer. Each node in this layer was used to represent each variable needed for identifying the risk of hypertension. The link weight attached to each node was 1 . Hence, the ANFIS model has six (6) nodes in this layer - one for each variable.

ii. Layer-2 (fuzzification layer): Each node in this layer, corresponds to one linguistic variable of each input node in layer-1. Thus, the nodes were the number of the membership values that specify the degree to which an input value belongs to in a fuzzy set. The c-means clustering algorithm was used to decide the initial number and type of membership functions (MFs) to be allocated to each of the input variables. The final shape of the MFs was fine-tuned, while the network learnt the data supplied. In all, there were 17 nodes corresponding to the 17 values for systolic and diastolic blood pressure (4 values each), risk factors ( 3 values) and the absence or presence of TOD, diabetes, and ACC (2 values each).

iii. Layer-3 (rule antecedent layer): Each of the nodes in this layer represents the antecedent part of the rules using a T-norm operator. The output of layer-3 nodes represents the firing strength of the weight $w_{j}$ attached to variable $x_{i}$ of the corresponding $j$ th rule. The input antecedent part of the rules and the output respectively is expressed as

$$
\begin{gathered}
\mathcal{R}_{j}: \text { If } x_{1}=A_{1 j} \text { and } x_{2}=A_{2 j} \ldots \text { and } x_{i}=A_{i j} \\
w_{j}=\min \left(\mu_{A_{1 j}}, \mu_{A_{2 j}}, \ldots, \mu_{A_{i j}}\right)
\end{gathered}
$$

where $A_{i j}$ is the crisp value chosen for an input variable $i$, $\mu_{A_{i j}}$ is the membership value (fuzzy logic value) of each variable's label and $\mathcal{R}_{\mathrm{j}}$ is rule $\mathrm{j}$.

iv. $\quad$ Layer-4 (rule strength normalization): every node $i$ in this layer was calculated on the ratio of the $j$-th rule's firing strength $w_{i}$ to the sum of all rules firing strength as shown in (2).

$$
\overline{w_{J}}=\frac{w_{j}}{\sum_{j} w_{j}},
$$

where $j$ is the number of rules $R, w_{j}$ is the firing strength of the $j$-th rule and $\bar{w}_{j}$ is the relative firing weight of the $j$ th rule. v. Layer-5 (rule consequent layer): Every node $j$ in this layer, has a node function expressed as an affine linear function of the input variable determined, using the least means square algorithm to estimate the consequent parameters, $\mathrm{a}_{i}$ and $\mathrm{a}_{\mathrm{o}}$, as expressed in the (3).

$$
\overline{w_{J}} \cdot f_{j}=\overline{w_{J}}\left(a_{0}+\sum_{j} a_{j} x_{j}\right)
$$

where $x_{j}$ are the linguistic values of the input variables and $\mathrm{a}_{0}, \mathrm{a}_{\mathrm{i}}$ are real numbers.

vi. $\quad$ Layer-6 (rule inference layer): the single node in this layer computed the overall output as the summation of all incoming signals from layer-5. The value of this output is estimated using the model.

$$
\text { Overall output }=\sum_{j} \overline{w_{J}} f_{j}=\frac{\sum_{j} w_{j} f_{j}}{\sum_{j} w_{j}},
$$

where $j=(1,2, \ldots, n)$.

In the second part of the construction of the ANFIS model using the backpropagation algorithm, the parameters needed for fitting the membership function $\mu_{A_{i j}}$ and the consequent parameters $\mathrm{a}_{\mathrm{j}}$ of the linear affine function were estimated via the gradient descent. The membership functions that were used are smooth antecedent Gaussian function which is shown as.

$$
\mu_{A_{i j}}\left(x_{j} ; c_{i j}, \sigma_{i j}\right)=e^{\left(-\frac{\left(x_{j}-c_{i j}\right)^{2}}{2 \sigma_{i j}{ }^{2}}\right)},
$$

where $c_{i j}$ and $\sigma_{i j}$ are the centre and spread of the Gaussian function respectively, $\mu_{\mathrm{A}_{\mathrm{ij}}}$ is the Gaussian membership function of variable $x_{j}$.

Table 5 gives a description of the antecedent part of the rules that was leveraged by the ANFIS model in Layer-3. The rules were motivated by the classification table for hypertension risk monitoring. The different values (labels) for each variable in Table 5 were combined using IF statement of the values for each label with the AND statement. The rules were based on the information collected about the relationship between the indicators of the risk of hypertension that are required to determine the risk of hypertension. The six variables that gave 17 nodes form the basic rules that yielded 384 rules and these were represented in Fig.1.

The MATLAB ANFIS Toolbox available in the MATLAB Software Release 2017a was used to simulate the ANFIS model required for the risk of hypertension and the model was validated. 
Table 5. Creation of antecedent part of the rules

\begin{tabular}{|c|c|c|c|c|c|}
\hline $\begin{array}{c}\text { Systolic } \\
\text { Blood } \\
\text { Pressure }\end{array}$ & $\begin{array}{c}\text { Diastolic } \\
\text { Blood } \\
\text { Pressure }\end{array}$ & $\begin{array}{c}\text { Number of Risk } \\
\text { Factors }\end{array}$ & $\begin{array}{c}\text { Target } \\
\text { organ } \\
\text { damage } \\
\text { (TOD) }\end{array}$ & Diabetes & $\begin{array}{c}\text { Associated } \\
\text { Clinical } \\
\text { Conditions }\end{array}$ \\
\hline Normal & Normal & None & Present & Present & Present \\
\hline Normal & Grade 1 & $1-2$ & Present & Present & Absent \\
\hline Grade 1 & Grade 2 & 3 and Above & Present & Absent & Present \\
\hline Grade 1 & Grade 3 & None & Present & Absent & Absent \\
\hline Grade 2 & Normal & $1-2$ & Absent & Present & Present \\
\hline Grade 2 & Grade 1 & 3 and Above & Absent & Present & Absent \\
\hline Grade 3 & Grade 2 & None & Absent & Absent & Present \\
\hline Grade 3 & Grade 3 & $1-2$ & Absent & Absent & Absent \\
\hline Normal & Normal & 3 and Above & Present & Present & Present \\
\hline Normal & Grade 1 & None & Present & Present & Absent \\
\hline Grade 1 & Grade 2 & $1-2$ & Present & Absent & Present \\
\hline Grade 1 & Grade 3 & 3 and Above & Present & Absent & Absent \\
\hline Grade 2 & Normal & None & Absent & Present & Present \\
\hline Grade 2 & Grade 1 & $1-2$ & Absent & Present & Absent \\
\hline Grade 3 & Grade 2 & 3 and Above & Absent & Absent & Present \\
\hline Grade 3 & Grade 3 & None & Absent & Absent & Absent \\
\hline Normal & Normal & $1-2$ & Present & Present & Present \\
\hline Normal & Grade 1 & 3 and Above & Present & Present & Absent \\
\hline Grade 1 & Grade 2 & None & Present & Absent & Present \\
\hline Grade 1 & Grade 3 & $1-2$ & Present & Absent & Absent \\
\hline Grade 2 & Normal & 3 and Above & Absent & Present & Present \\
\hline Grade 2 & Grade 1 & None & Absent & Present & Absent \\
\hline Grade 3 & Grade 2 & $1-2$ & Absent & Absent & Present \\
\hline Grade 3 & Grade 3 & 3 and Above & Absent & Absent & Absent \\
\hline
\end{tabular}

\section{B. System Design Modelling of Hypertension Risk} Monitoring System

Following the development of the ANFIS model that was needed for classifying the risk of hypertension based on the interview with the expert cardiologists on the steps required for monitoring hypertension, there is the need to capture and manipulate information necessary for monitoring hypertension risk and thus, implement the system. The system created a diary for each user through which their personal and clinical information was provided.

The system was expected to constantly collect information regarding the blood pressure of individuals and prompt the hypertension risk assessment model to determine the risk of hypertension if an individual is monitored to be hypertensive on three consecutive times. The moment an individual is monitored and discovered to be hypertensive for three consecutive readings, the system checks the risk factors and other clinical information and uses the values provided by the patient to determine the risk of hypertension. As long as an individual's blood pressure is normal, there is no need to verify the risk of hypertension in the individual.

Use-Case diagram is a requirement discovery technique that was used in modelling the interactions between the system and the actors (users). In its simplest form, a use-case identifies the actors (users) involved in an interaction and the names and the types of interactions involved. These use case scenarios were used to present the system requirements of the hypertension risk monitoring system that would make use of the data model needed for the database from the front-end of the system. Using the scenarios afforded the opportunity to obtain the realistic description of the workflow of the system, which was to explicitly describe the intentions and actions of the users.

Tables 6 and Table 7 give the descriptions of the use case scenarios of the data insertion and data query made by users of the system. Based on the enquiries made during the interview with the cardiologists, it was observed that the proposed monitoring has two users, namely: the primary users, the cardiologists or general physicians and the system administrator.

When the primary users register, a profile is created, which is used to create a diary for the user into which a $\log$ of the values of the blood pressure monitored is recorded with other important information. This information can be manipulated by the system to provide the necessary assistance that the patients require, while the cardiologists/general physicians can be able to view the information stored on the patients and contact them if need be in the case of a foreseen emergency situation from any remote location. 
Table 6. Data Insertion Use Case for Users

\begin{tabular}{|c|c|}
\hline $\begin{array}{l}\text { Use Case } \\
\text { Name }\end{array}$ & Data Insertion \\
\hline Description & $\begin{array}{l}\text { Scenario to illustrate data insertion for hypertension } \\
\text { risk monitoring system }\end{array}$ \\
\hline Actors & Patients, Administrator, Cardiologist \\
\hline Scenarios & $\begin{array}{l}\text { 1. Administrator pre-registers the cardiologists by } \\
\text { providing personal and hospital-based } \\
\text { information } \\
\text { 2. Patient registers to the system diary } \\
\text { 3. Patient provides personal information } \\
\text { 4. Patient provides information on risk factors } \\
\text { 5. Patient provides information on etiological } \\
\text { factors } \\
\text { 6. Patient provides clinical information } \\
\text { 7. Cardiologist provides login details (user Id and } \\
\text { password) before accessing patients' } \\
\text { information }\end{array}$ \\
\hline
\end{tabular}

Fig.2. shows a description of the use case diagram for the use case scenarios defined in Tables 4 and Table 5. The diagram shows the users (actors) as stick-men which were used to identify the patients, monitoring system and the cardiologists who are expected to interact with the system. The oval structures in the diagram show the different activities that the users can carry out on the system. The patients and cardiologists must log into the system before they can perform any action while every information on the patients can be viewed by the cardiologists. The cardiologists cannot edit information provided by patients.

Table 7. Data Query Use Case for Users

\begin{tabular}{|c|c|}
\hline $\begin{array}{l}\text { Use Case } \\
\text { Name }\end{array}$ & Data Query \\
\hline Description & $\begin{array}{l}\text { Scenario to illustrate data query for patients and } \\
\text { cardiologists. }\end{array}$ \\
\hline Actors & Cardiologists, Administrator \\
\hline Scenario & $\begin{array}{l}\text { 1. System checks for user identification after } \\
\text { providing login details: } \\
\text { If a user is valid, the system displays a } \\
\text { menu for actions. } \\
\text { If a user is not valid, the system rejects user } \\
\text { access. } \\
\text { 2. Cardiologist views the number of patient } \\
\text { records stored on the system including } \\
\text { information provided by the patients. } \\
\text { 3. Patients are able to determine the risk of } \\
\text { hypertension. } \\
\text { Patients are required to perform incomplete } \\
\text { 5. Cardivities. }\end{array}$ \\
\hline
\end{tabular}

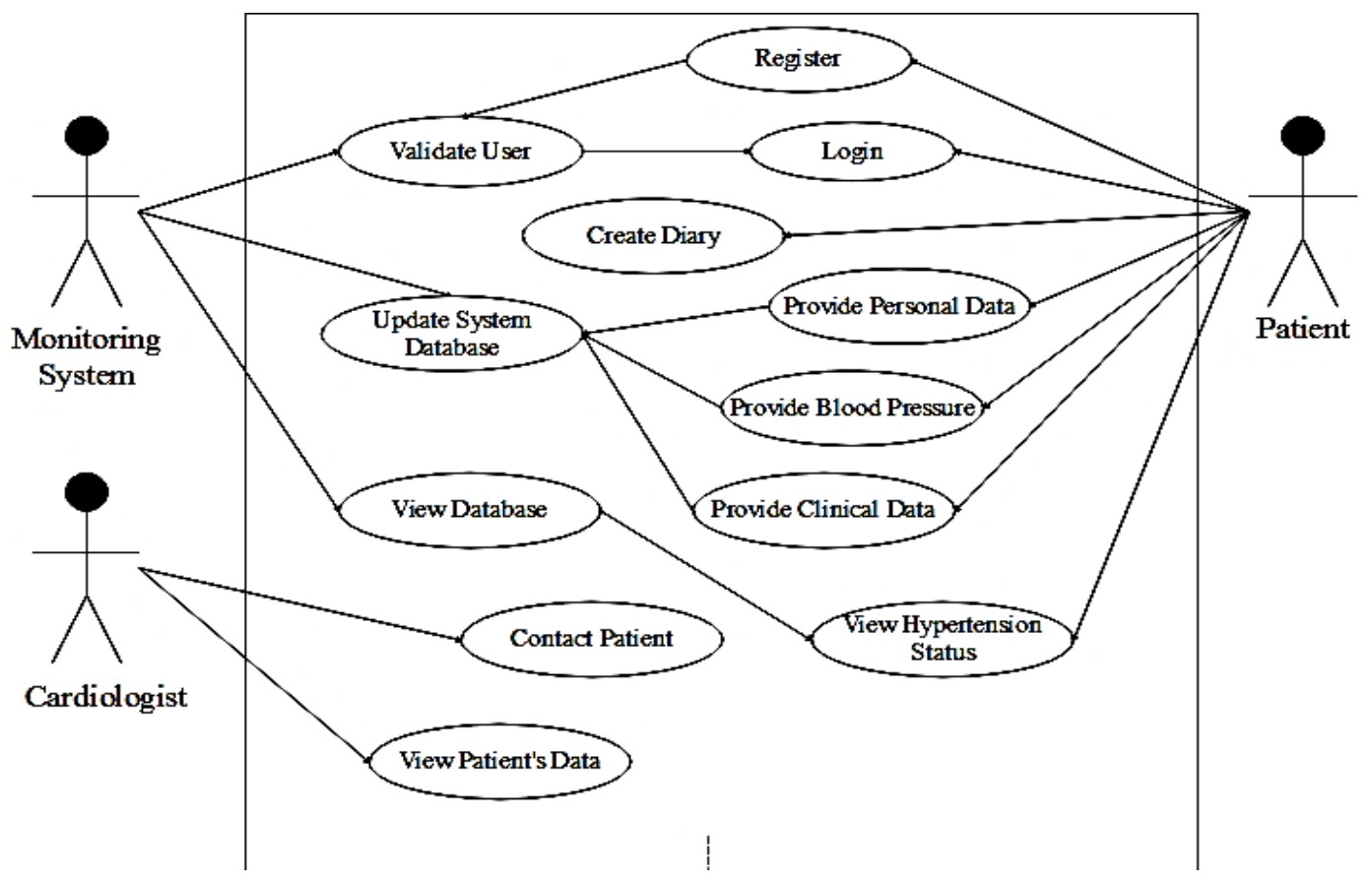

Fig.2. Use case Diagram for Monitoring System Users

The design of the hypertension risk monitoring system's architecture was developed to create a clearer picture of the structure of the entire risk monitoring system. The system architecture of the hypertension risk monitoring system consists of a set of hardware that is defined in accordance with the requirements and specifications of the monitoring system. The system architecture gives a description of the relationship that exists between the different hardware that continues to make up the system's architecture. Fig.3. shows the system architecture of the mobile-based hypertension risk monitoring system. The architecture is characterised mainly by the system components and the relationship that exists between them. The system architecture of the system is a three-tier architecture that was divided into three main parts, including the client side, middle tier, and the server side. The client side is the part of the system where the users of the system will interact with 
the application. This will happen via the Uniform Resource Locator (URL), which directs activities to the application directory residing in the application server.

The middle-tier is where the application server that manages the Mobile-based system's service resides. It is integrated with the business logic that contains the hypertension risk monitoring ANFIS model. This logic system is developed for the purpose of mapping the input data collected from the patients to be required output that was needed for identifying the risk of hypertension. The cardiologists will simply query the database for information stored for each patient that is available in the database of the monitoring system.
The server side contains the database server that manages the storage and retrieval of relevant information. The hosting server is accessed by the system administrator for creating new profiles and for managing the services provided to the system via the hosting service provider. In order to hide most of the internal workings of the prototype system from users, the objectoriented concept of encapsulation was leveraged. The Object-Oriented Programming technique was used to model the real world entities that are involved in the system. Based on this, an interface was provided to allow users to perform data capture and other processing activities using mobile-based devices.

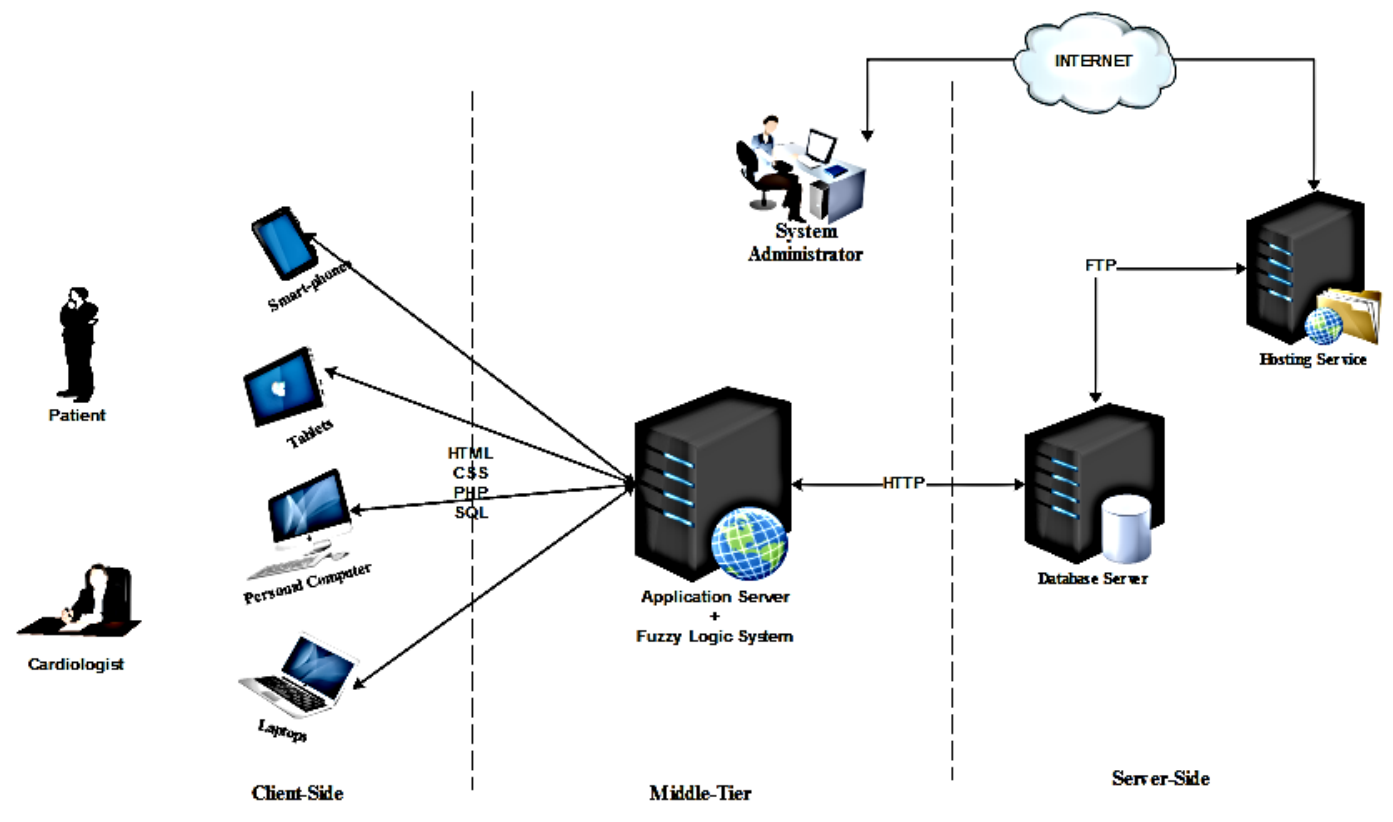

Fig.3. System Architecture for the Hypertension Risk Monitoring System

Based on system requirements, Fig.4. shows the system framework of the information includes primary or secondary hypertensive situations based on the presence or absence of hypertension risk and etiological factors. Whenever a patient's blood pressure is higher than normal, indicating hypertension, for three consecutive times, the monitoring model for hypertension risk required to evaluate the information. The patient's risk of hypertension is provided based on the information available and if a patient is discovered to be hypertensive and the risk stratification performed, then a notification will be made to the patients and doctors in order to be aware of the state of the patient's health.

As a result, the doctor may decide to contact the patient in order to provide any necessary medical advice. The doctor can also view the trend of the variation in the blood pressure as recorded on the chart used to monitor the values of the blood pressures included by the patients.

The BP_HRMSystem provided a well designed framework that integrated various elements required from designing the concept to the implementation and is shown on Fig.4. This system framework involves the registration of users, keeping a diary on a patient, plotting a chart on the patient's blood pressure, determining the patient's risk outcome, patient's medication and investigation (patient's history), viewing the patient's record by the patient and the medical practitioner, and also communication between patient and the medical practitioner.

\section{Implementation of the Mobile-Based System - BP_HRMSystem}

The mobile-based system for hypertension risk monitoring was implemented using a combination of Java, Extensible Mark-Up Language (XML) and JavaScript programming languages, for the front-end side of the mobile application code while the JavaScript Object Notation (JSON) was used to implement the database of the mobile application.

The mobile application was written using mainly XML and Java which supports the majority of the mobile browsers and were used to implement the mobile application for monitoring hypertension risk using the Google Android Studio Integrated Development Environment (IDE). XML was required for defining the content of the mobile application and was used to 
implement the layout of the content of the interface for the BP_HRMSystem, following a rapid application development. The Java programming language was used to provide the functionality to the contents within the layout provided using the XML programming language by encapsulating codes that describe the necessary actions to be performed by the contents embedded in the interface.

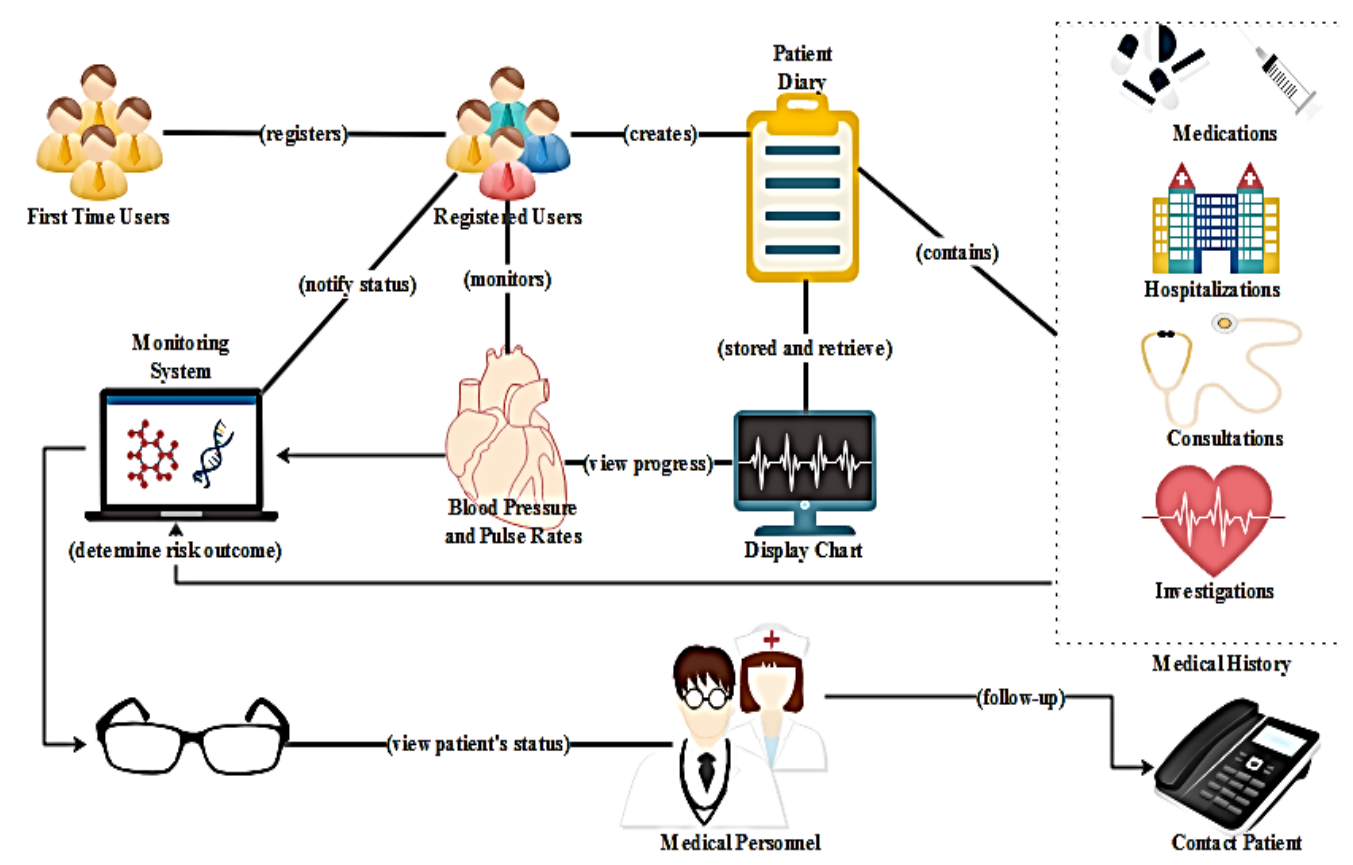

Fig.4. System Framework for hypertension risk monitoring system

The BP_HRMSystem for hypertension risk monitoring was implemented to run live and can also run in a local host. The development of the mobile-based application was done on a Windows 1064 Bit Operation System running on a 4 GB RAM Intel Based processor of 2.4 GHz. The mobile-based system was also implemented using the Adobe Dreamweaver ${ }^{\circledR}$ IDE Software and the Notepad ++ editor.

Three hundred (300) dataset collected from patients between October and November 2017, were used in evaluating the BP_HRMSystem mobile-based system and the result gives $100 \%$ accuracy.

There is a need for the patients to identify whether is hypertensive or not and know the risk involved, so as to help in early detection and give the patients opportunity to have an alternative pattern to lifestyle and dietary needed in order to avert the onset of hypertension and/or its related cardiovascular diseases.

BP_HRMSystem acts as the personal health information system which allows medical practitioners to view current and history condition of the patient, and give advice to the patient. The patient also views the records to know the situation of the health concerning hypertension. It also acts as medical guidance (education) that includes the communication platform and the medical knowledge database, being controlled by an Administrator.

The applications developed for BP_HRMSystem were stored in an application server while the data managed by the system was stored in a database server in order to prevent unauthorized access to the system implemented.
The application server handled a number of processes based on the requests of the users, which were generalised into the following functionalities: information capturing; information access; central database system; and timely alerts.

The database for the mobile-based hypertension risk monitoring system was created using the Structured Query Language (SQL) on a MySQL database system. This is used to create the database tables representing each entity (or object/class) within the system alongside their fields (attributes). The primary key of each table was also defined in the database implementation in addition to different queries necessary for performing different actions and requests made by the users of the system.

\section{RESUlTS AND DISCUSSION}

\section{A. Results}

The designed architecture and framework guided the implementation of the database and the front-end of the BP_HRMSystem, which is developed for monitoring hypertension risk.

The data from an individual or user were kept in a diary. A diary was created for each user through which their personal and clinical information was provided. The system, BP_HRMSystem, checks whether the user is hypertensive or not, as it properly classifies the blood pressure of individuals (normal, grade I, grade II and grade III). The SBP, DBP, risk factors and other clinical 
information provided by the patient to determine the risk of hypertension were used and correctly classified as low, medium, high and very high cases among the hypertension risk of the patients. Also, it indicates whether the patient is having primary or secondary hypertension.

Fig.5. shows the main menu screenshot of the hypertension risk monitoring system that comprises the patient's, doctor's and administrator's interfaces.
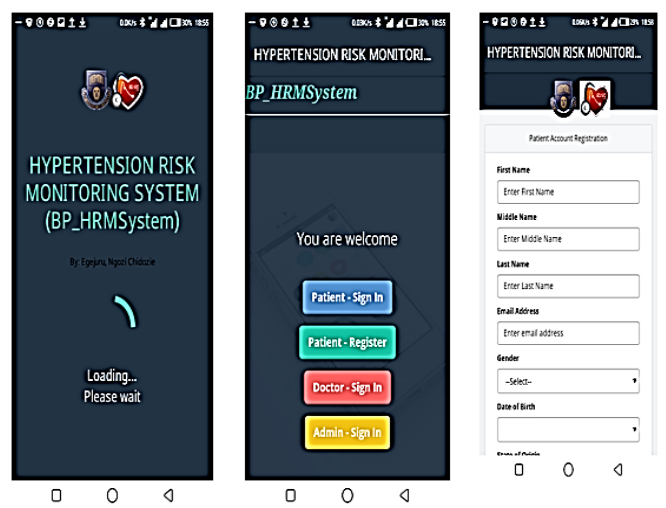

Fig.5. BP_HRMSytem Interface showing various Activities

Fig.6. is the screenshot of what the patient used to provide information regarding the state of their health. To input data into the system, which is based on the requirements of the WHO/ISH guidelines for classifying hypertension risk, are divided into eight sections. All sections must be completed before the user can determine the state of his or her health.

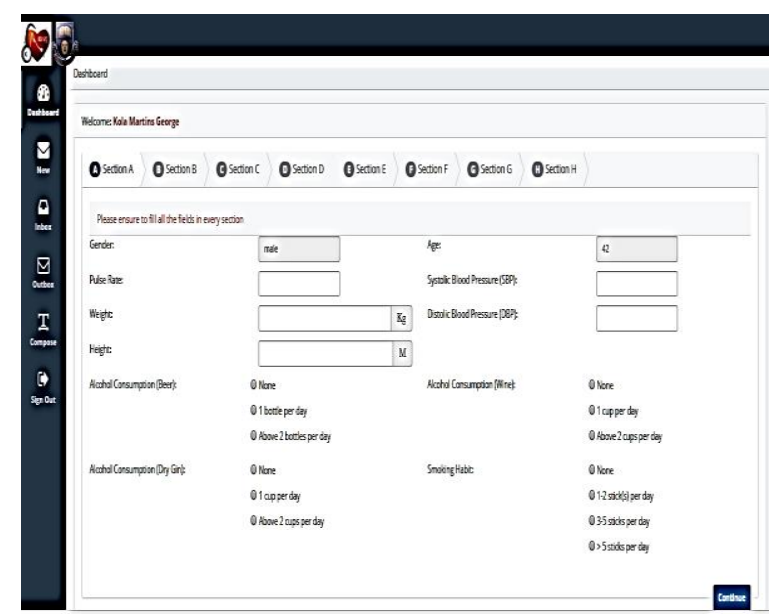

Fig.6. Patient Dashboard for Providing Information about Hypertension

Fig.7. shows the screenshot of the results of the analysis of the information provided by the patients. The blood pressure of the user is shown as a graph presenting the rise and fall of systolic and diastolic blood pressure levels of patients, from inception.
Fig.8. shows the screenshot of the dashboard of the system administrator. It displayed the activities performed by the administrator, comprising: requests, managing doctors and managing administrators. Every hospital registered to the system has its own administrator who in turn is responsible for registering the doctors or any other medical practitioner working with them that needs access to the patient's record.

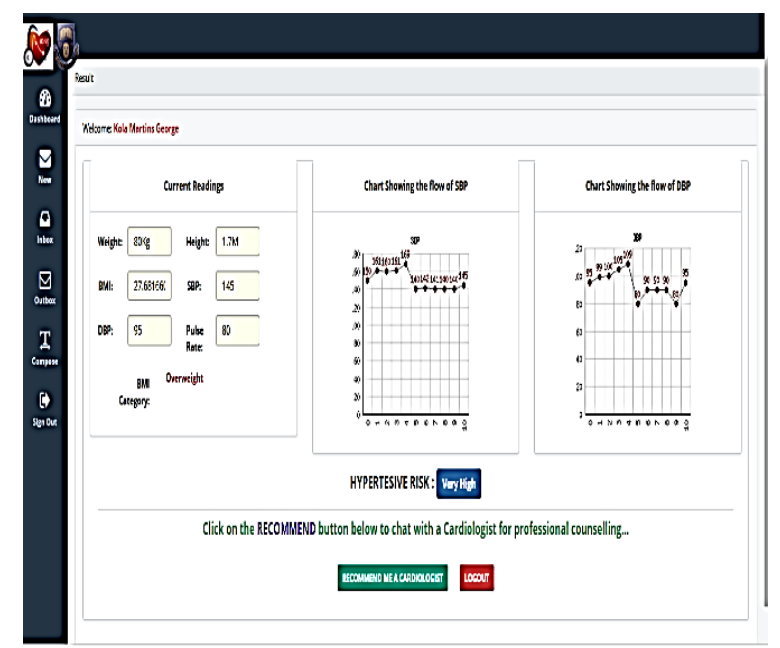

Fig.7. Patient Dashboard for viewing Results about Hypertension

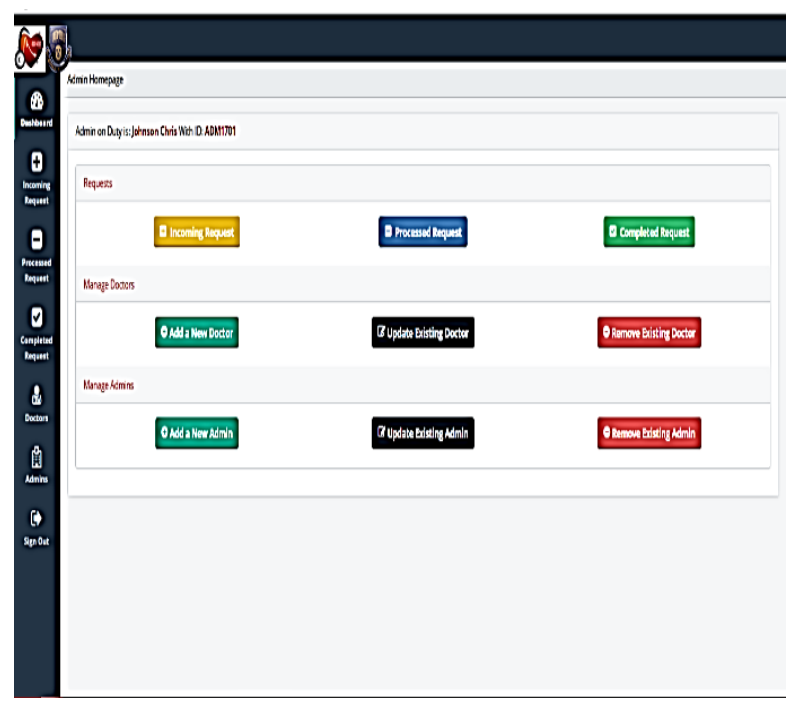

Fig.8. Administrator's Dashboard for Activities to be carried out

Fig.9. shows the screenshot of the incoming alert which was accessed by the administrator and is in turn, forwarded to the available doctor in order to attend to the patients.

Fig.10. shows the screenshot of the doctor's dashboard which was used for accessing the information of patients assigned to them following the process of incoming alerts for their immediate medical attention. 


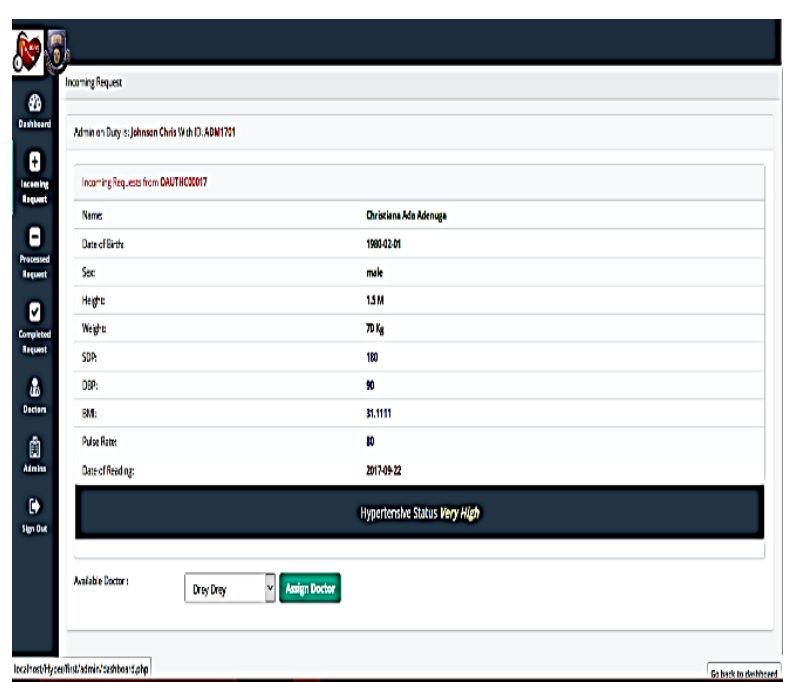

Fig.9. Administrator's Dashboard for assigning Doctors to Patients

\section{B. Discussion}

In this study, a mobile health monitoring system for hypertension and its risk called BP_HRMSystem was developed, which can dynamically monitor the patient's blood pressure and the hypertension risk anytime, anywhere and will also help in receiving an alert from the medical practitioner or communicate with the patient as the need arises. It was developed to enable patients to check their hypertension status at anytime and from any location.

From Fig.7. all the 33 variables identified and confirmed by specialists (cardiologists and nephrologists) as stated in the questionnaire were captured. The variables were able to provide rightful information required for proper classification and monitoring of hypertension and its hypertension risk. Fig.6. showed the classification of hypertension risk, even BMI. It plots the patient's measured blood pressure to show the patient at a glance the blood pressure flow. The administrator handles the management of the system, which includes managing the Doctor, users, and messages (Fig.8. and Fig.9.). The Doctor can view patients' records but cannot modify them. When the Doctor responds, communicate with the patients and make some recommendations, the incoming alert will pass through the administrator before reaching the patient. Fig.10. displays detailed information on the patient, assigned to a Doctor by the administrator. This will assist the Doctor in confirmation and taking decisions.

BP_HRMSystem acts as the personal health information system which allows medical practitioners to view the current and historical condition of the patient, and give advice to the patient. The patient also views the records to know his/her situation. The system also acts as medical guidance (education) that includes the communication platform and the medical knowledge database, being controlled by an Administrator. This database allows the patient to be educated or acquire knowledge of the disease and know what action should be taken in case of new development. The patient and the medical practitioner use the communication platform, to send messages and seek advice.

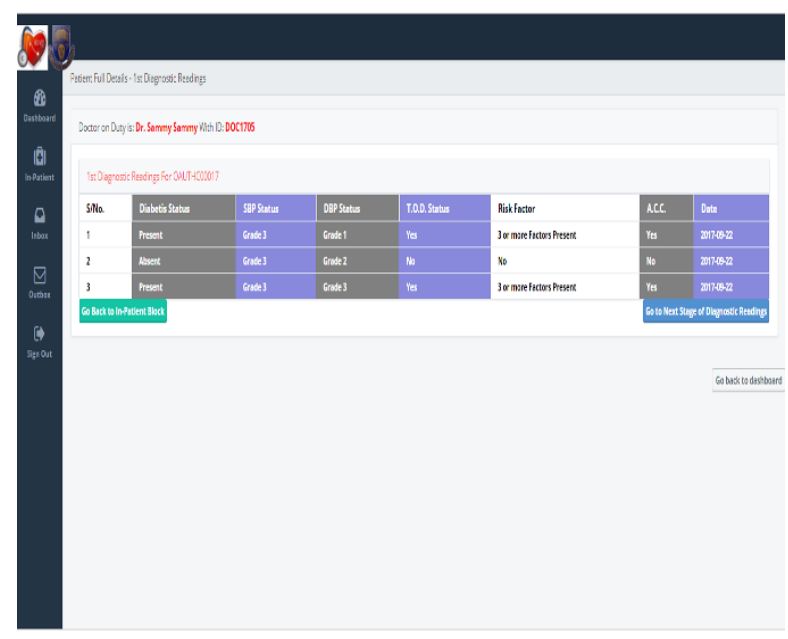

Fig.10. Doctor's Dashboard for viewing assigned Patients

The Identified results are shared with physicians via mobile and are saved online in the records of the patient. All these are monitored by an Administrator. Validation results matched with the results stated in the paper, given $100 \%$ accuracy. The rules generated by ANFIS using MATLAB Tools, which were implemented in the mobile-based system, has shown very high prediction accuracy. The system has been tested and validated on 300 patients dataset collected from OAUTHC, SDAH and $\mathrm{UCH}$ in Nigeria.

\section{CONCLUSION}

The mobile-based monitoring system for hypertension risk, BP_HRMSystem was developed so as to make the system easily accessible to users from any remote location. The research also incorporated additional variables for classifying hypertension risk, which could form the basis for controlling and monitoring hypertension. In addition, the research also developed a mobile-based system that will help individuals to know their risk status and also assist physicians in the classification and monitoring of patient's hypertension risk with ease. This study also provided a healthcare system that explicitly classifies human blood pressure, maintain a diary that is plotted to show the patient's blood pressure flow that is applicable both in developing and developed countries. The BP-HRMSystem classifies the blood pressure of patient correctly by classifying Normal, grade I, grade II and grade III as applicable to the patient and was able to properly distinguish low, medium, high and very high cases among the hypertension risk of the patients.

This will help in giving early warning and educating the patient. This will assist the medical practitioners in quick decision making, early detection, classification, controlling, monitoring and managing hypertensive patients, thereby bringing development in healthcare. 


\section{REFERENCES}

[1] K. Wolf-Maier, R. S. Cooper, H. Kramer, J. R Banegas, S. Giampaoli, M. R. Joffres, et al. (2004). Hypertension treatment and control in five European countries, Canada, and the United States. Hypertension; 43: 10-17.

[2] G. Ogedegbe, S. Fernandez, L. Fournier, S. A. Silver, J. Kong, S. Gallagher, et al. (2013). The Counseling Older Adults to Control Hypertension $(\mathrm{COACH})$ trial: Design and Methodology of a Group-based Lifestyle Intervention for Hypertensive Minority Older Adults. Contemporary Clinical Trials 35(1): 70 - 79.

[3] X. Y. Djam and Y. H. Kimbi (2011). Fuzzy Expert System for the Management of Hypertension. The Pacific Journal of Science and Technology 12(1): 390 - 402.

[4] A. A. Imianvan and J.C. Obi (2012). Cognitive NeuroFuzzy Expert System for Hypotension Control. Computer Engineering and Intelligent Systems 3(6): 21 - 31.

[5] K. Obahiagbon and B. B. Odigie. (2015). A Framework for Intelligent Remote Blood Pressure Monitoring and Control System for Developing Countries. Journal of Computer Sciences and Applications 3(1): 11 - 17.

[6] World Health Organisation (2011). WHO Maps: NonCommunicable Disease Trend In All Countries. World Health Global Report, World Health Organisation.

[7] World Health Organisation (2015). Global Health Observatory (GHO) Data: Raised Blood Pressure. Available from http://www.who.int/gho/ncd/risk_factors/blood_pressure _prevalence_text/en/ on June 25, 2016.

[8] A. V. Chobanian, G. L. Bakris, H. R. Black, W. C. Cushman, L. A. Green., J. L. Izzo, et al. (2003). The $7^{\text {th }}$ Report of the Joint National Committee on Prevention, Detection, Evaluation, and Treatment of High Blood Pressure: The JNC 7 report. Journal of the American Medical Association 289: 2560 - 2672.

[9] I. A. Bani (2011). Prevalence and Related Risk Factors of Essential Hypertension in Jazan Region, Saudi Arabia. Sudanese Journal of Public Health 6(2): 45-50.

[10] A. G. Logan, W. J. McIsaac, A. Tisler, M. J. Irvine,.., A. Saunders, A. Dunai, et al. (2007). American Journal of Hypertension, 20(9): 942-948, https://doi.org/10.1016/j.amjhyper.2007.03.020

[11] K. R. Lorig, D. S. Sobel, P. L. Ritter, D. Laurent, and M. Hobbs (2001). Effect of a self-management program in patients with chronic disease. E_ Clin Pract; 4: 256-262.

[12] P. Srivastava, and A. Srivastava (2012). Spectrum of Soft Computing Risk Assessment Scheme for Hypertension. In International Journal of Computer Applications. 44(17): $23-30$.

[13] P. Srivastava, A. Srivastava, A, Burande, and A. Khandelwal (2013). A Note on Hypertension Classification Scheme and Soft Computing Decision Making System. ISRN Biomathematics: 1 - 11.

[14] A. Kaur and A. Bhardwaj (2014). Genetic Neuro-Fuzzy System for Hypertension Diagnosis. International Journal of Computer Science and Information Technologies 5(4): 4986 - 4989.

[15] H. Joseph and J. Tan (2002). "The Evolving Face of
Telemedicine and e-Health: Opening Doors and Closing Gap's in E-Health Services Opportunities and Challenges", Proceedings of the $36^{\text {th }}$ Hawaii International Conference on System Sciences (HICSS'03), IEEE, 2002

[16] Jen-Her Wu, Shu-Ching Wang, and Li-Min Lin (2005). "What Drives Health Care? An Empirical Evaluation of Technology Acceptance", Proceedings of $38^{\text {th }}$ Hawaii International Conference on System Sciences, IEEE, 2005

[17] Gunther Eysenbach (2001). "What is e-Health?", Journal of Medical Internet Research, 2001.

[18] R. Jones, R. Rogers, J. Roberts, L. Callaghan, L. Lindsey, J. Campbell, et al. (2005)., "What Is eHealth (5): A Research Agenda for eHealth Through Stakeholder Consultation and Policy Context Review" Journal of Medical Internet Research, Vol 7, Issue 5, 2005

[19] J. Cheng and R. Greiner (1999). Comparing Bayesian Network Classifiers. In Proceedings of the Fifteenth Conference on Uncertainty in Artificial Intelligence. Morgan Kaufmann Publishers Inc., Alberta, Canada: 101 -108 .

[20] Z. Benyó, P. Várady, B. Benyó and B. Tóth (1999). Remote Patient Monitoring System Based on an Industry Standard Fieldbus. In 2nd World Congress on Biomedical Communication, Amsterdam: 5 - 8 .

[21] WHO, "Strategy 2004-2007: eHealth for Health-care Delivery". www.who.int/eht/en/eHealth_HCD.pdf

[22] N. C. Egejuru, P. D. Mhambe, J. A. Balogun,., F. Komolafe, and P. A. Idowu (2017). Osteoporosis Risk Predictive Model Using Supervised Machine Learning Algorithms. Science Publishing Group, Engineering and Applied Science.

[23] J. Chalmers, S. MacMahon, G. Mancia, J. Whitworth, L. Beilin, L. Hansson, et al. (1999). 1999 World Health Organisation-International Society of Hypertension Guidelines for the management of hypertension. Guidelines sub-committee of the World Health Organisation. Clinical and experimental hypertension. New York: USA: 1009 - 1060.

[24] A. Bolaji (2014). Simulation of a Real-Time Mobile Health Monitoring System Model for Hypertensive Patients in Rural Nigeria. African Journal of Computing and ICT 7(1): $95-100$.

[25] J. O. Egwaile, O. I. Omoifo, O. O. Odia, and O. Okosun (2016). Development of a Real Time blood pressure, temperature measurement and reporting system for inpatients. International Journal of Physical Sciences 11(17), 2016, $225-232$.

[26] P. A. Idowu, S. O. Ajibola, and J. A. Balogun, Development of a web based Cardiovascular Disease Risk Monitoring System. Ife Journal of Information Communication Technology 1(1), 2016, 4 - 16.

[27] A. D. Lopez, D. Andrea and A. R. Carlos (2006). Global and regional burden of disease and risk factors: Systematic analysis of population health data. Lancet 367(9524): $1747-1757$.

[28] B. Ordinioha, (2016). The prevalence of hypertension and its modifiable risk factors among lecturers of a medical school in Port Harcourt, south-south Nigeria: implications for control effort. Nigerian Journal of Clinical Practice 16(1): 1 - 11 


\section{Authors' Profiles}

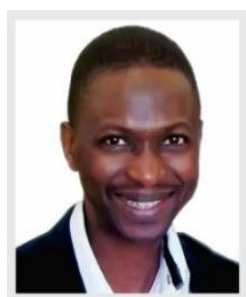

Ogunalde Oluwadare is a Reader at the Department of Physiological Sciences, College of Health Sciences Obafemi Awolowo University, Nigeria. $\mathrm{He}$ is a fellow of West African College of Physicians. He also has M.Sc. and Ph.D in Physiological Science. His research area is cardiology and cardiovascular physiology. He has over 30 publications to his credit in both local and international journals.

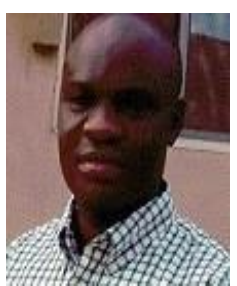

Peter A. Idowu is a Senior Researcher in the Department of Computer Science and Engineering, Obafemi Awolowo University, Nigeria. Dr Idowu received his B.Sc. (Computer Science with Economics) from Obafemi Awolowo University, Ile-Ife, Nigeria and MPhil (Computer Science) from Aston University, Birmingham, United Kingdom in 1998 and 2009 respectively. He also has
$\mathrm{PhD}$ (Computer Science) from Obafemi Awolowo University, Ile-Ife, Nigeria in 2012. His research focus is on applied computing that is application of computing to address and solve health related problems in Sub Saharan Africa. He has over 70 publications to his credit in local journals, international journals and referred conference proceedings. $\mathrm{He}$ is currently researching into HIV/AIDS, Disease modelling and cloud computing in health care delivery.

$\mathrm{He}$ is also a Member of British Computer Society, Internet Society Nigeria Chapter, Nigerian Computer Society, Computer Professional Registration Council of Nigeria, Nigerian Young Academy, International Geospatial Society, International Association of Engineers and International Federation of Information Processing WG 9.4. His research interest includes Health Informatics, Data Modelling, Software Engineering, Geographical Information System, and Informatics. Within the last five years,

Dr Idowu has successively trained over 15 graduate students (both Master and Doctoral students). He is blessed with three Research Associates; Praise, Vicky and Peter. He enjoys reading and driving.

How to cite this paper: Ngozi C. Egejuru, Oluwadare Ogunlade, Peter A. Idowu, " Development of a Mobile-Based Hypertension Risk Monitoring System", International Journal of Information Engineering and Electronic Business(IJIEEB), Vol.11, No.4, pp. 11-23, 2019. DOI: 10.5815/ijieeb.2019.04.02 